\title{
Researching New Media and Social Diversity in Later Life
}

Givskov, Cecilie; Deuze, Mark

Published in:

New Media \& Society

DOI:

$10.1177 / 1461444816663949$

Publication date:

2018

Citation for published version (APA):

Givskov, C., \& Deuze, M. (2018). Researching New Media and Social Diversity in Later Life. New Media \& Society, 20(1), 399-412. https://doi.org/10.1177/1461444816663949 


\section{Researching new media and social diversity in later life}

new media \& society 2018, Vol. 20(I) 399-412

(c) The Author(s) 2016

Reprints and permissions: sagepub.co.uk/journalsPermissions.nav DOI: |0.1 I77/|46|4448|6663949 journals.sagepub.com/home/nms

@SAGE

\title{
Cecilie Givskov
}

University of Copenhagen, Denmark

\section{Mark Deuze}

University of Amsterdam, The Netherlands

\begin{abstract}
As societies are ageing and mediatizing at the same time, it becomes both timely and relevant to develop particular perspectives on the role and meaning of media for older people. The diversity and inequality in the lived experience of the ageing population in the new media environment constitute a blind spot in current research. In this essay, we bring literatures of (cultural) ageing studies and (new) media studies into conversation with each other by asking what future directions for research on older people and their media lives from the particular perspective of social diversity could be. We propose three key interventions: developing a focus on social stratification and inequality broadly conceived; designing research with a life course perspective rather than reducing people to age groups; and focusing empirical work looking at the various ways people 'do' media in an ensemblematic way.
\end{abstract}

\section{Keywords}

Ageing, digital divide, life course, media theory, media use, mediatization, social stratification

\section{Introduction}

With balanced attention to the dominant demographic and socioeconomic trends in the world today, societies are ageing (Wilson, 2001), social inequality is rising (Piketty, 2014) and we are witnessing a liquefaction of the life course (Bauman, 2005); the importance of

\section{Corresponding author:}

Cecilie Givskov, Department of Media, Cognition and Communication, University of Copenhagen, Karen Blixens Vej 4, 2300 Copenhagen S, Denmark.

Email: cecilieg@hum.ku.dk. 
focusing on the role of identity and culture with respect to inequality in later life is currently stressed among scholars of ageing (Formosa and Higgs, 2013; Higgs and Gilleard, 2006). As people get older, they face an increasingly complex world largely on their own, using technology in general and media in particular to navigate the white-water of later life. The ubiquity and pervasiveness of media are significant in the way people structure, experience and give meaning to their daily lives while media have become increasingly powerful as a social institution that people and other institutions have to orient themselves towards (Hjarvard, 2008). Contemporary media-theoretical interventions such as mediatization (Couldry and Hepp, 2013; Lundby, 2009), polymedia (Madianou and Miller, 2013) and media life (Deuze, 2012) articulate media with a historical process where media become intrinsic to social institutions and practices, shaping (and being shaped by) the way we feel, think and interact, and the way all aspects of the social can be arranged. The mediatization of society begs questions of how the media environment is formative regarding reducing or amplifying social inequalities (Couldry, 2012: viii; Hepp and Hasebrink, 2013: 15-17) - specifically related to ageing and in old age.

Older people constitute the fastest growing group in the population of developed societies that is highly diverse in terms of economic, social and cultural resources. ${ }^{1}$ They are also the fastest growing segment of users of Internet, social media and smartphones worldwide (Eurostat, 2015; Saul, 2014; Smith, 2014). People orient themselves to post-retirement life, old age and later-life identities in different ways and work through different types of (economic, social, cultural) exclusion in society while navigating their roles, opportunities, wants and needs in all of this in media. A task for media scholars is to find ways to correspondingly theorize and analyse older people's lives in media, whereas ageing studies need to align themselves with developments in media theory in order to adequately assess the comprehensively mediatized life people are leading today.

Within media studies, the concern for later life has generally been translated into research on digital divides, and into the role of digital media in compensating for physical, mental and social dependencies. Embedded in such studies is a generally progressive narrative, either by complicating the role media play in life or by working through scenarios of how media can contribute to alleviating (real or perceived) problems in later life. The diversity in lived experience of older people in the new media environment constitutes a blind spot in current research (Hagberg, 2012; Quinn, 2014; Richardson et al., 2011). We address this research lacuna by asking what future directions for research on older people and their media lives could be by bringing into conversation emerging perspectives from social stratification studies, ageing studies and media and communication studies. Our review suggests that exploring media use on an everyday level sensitive to social and cultural differences among older people would be a critical step to take in order to qualify studies on digital and social inequality, their possible interconnections and supposed consequences for the quality of later life. We will outline three major pitfalls and promises in existing research on older people's media use and role in society in order to identify what we see as ways of theorizing and studying older people's lives in media that do justice to their prominent and differentiated position in society: 
1. Cultural approaches to social diversity and inequality in order to move beyond reducing difference to economic indicators;

2. Life course perspective: linking mediatization and other historical trends with biographical experiences in order to move beyond homogenizing older people into age groups;

3. The media ensemble: looking at the various (and varying) ways people 'do media' and give meaning to their ensemblematic media use with appreciation of economic, social and cultural resources in order to move beyond documenting older people's use of distinct media strictly in terms of access; time spent (such as, number of hours watching television and surfing the Web); operating technology, searching and handling information; or practising cognitive or motor skills.

\section{The transformation of ageing and cultural approaches to social diversity and inequality}

Our first intervention focuses on the operationalization of social stratification and inequality broadly conceived in studies of later life. Beyond traditional conceptualizations of inequality and stratification largely determined by property and socioeconomic status, we follow Formosa and Higgs' (2013) call to advocate cultural approaches, specifically focusing on how older people make sense of self, other and their world beyond decline or dependency. Rather than seeing old age (like class) as something that happens to people, later life today can be considered varied and dynamic. Some experience affluent later lives, while others face an additional phase of precariousness; some stay healthy long into old age, while others go though many years of decline and frailty. All of this depends on the utilization of individual resources and experience tied up with key transformations in society as the developed world moves from a more or less stable, 'solid' modern state to a way of living in a liquid modern context, described by Zygmunt Bauman (2005) as 'a society in which the conditions under which its members act change faster than it takes the ways of acting to consolidate into habits and routines' (p. 1).

As work and retirement depend more on individual choices that are neither determined nor secured through the nation-state, the firm or the family, questions of identity and belonging gain new significance for later life (Higgs and Gilleard 2006: 223). Some older people will still depend on the state; some have the opportunity to build their own lifestyles and fashion their own identities, just as socially differentiated as at earlier ages. Identities of later life are constructed around the agency associated with the 'third age' conceptualized as a life stage (post-retirement and before the onset of substantial decline and frailty) rather than a specific phase and age (Gilleard and Higgs, 2011). The vitality of third age can be set against the backdrop of simply being 'old': to the dependency and death of the fourth age, 'defined in the collective imagination by its negativity and otherness' (Higgs and Gilleard, 2015: vii). It is this cultural field of later life that needs our attention, where stratification occurs between, on one hand, the identity have-nots who embody the fourth age (the frail old, the dying and those unable to participate in economic as well as digital life) and, on the other hand, the more or less affluent and differentiated identity-haves as part of the cultural mainstream (Higgs and Gilleard, 2006: 220). 
Part of surviving in contemporary capitalism and society depends on the successful navigation of the multiple media environment (Deuze, 2012: 165). Mass media in general and personal media in particular play a profound role in contemporary processes of sense-making, performing and shaping identities, forming and maintaining relationships, as well as simply being in (and navigating through) the world. As formulated by Lunt and Livingstone (2011), critical media literacy has become the prerequisite for people to participate effectively in society; at the same time, this can only be realized in and through social practices' (p. 136). It is on this level of practice where personal, mobile and social media in particular provide the interfaces of people's relationships with each other as well as with service providers, businesses and the state. By utilizing media as a cultural resource, individuals in the mediatized context become 'the result as well as the producer of its networks, situation, location and form' (Beck et al., 2003: 25; italics in original). Grounded in this dialectic, people can be seen as caught by a double bind in media: from the increasingly prominent role of information and communication technologies (ICT) intensified by the on-going dismantling of the welfare state and the individualization of society (Bauman, 2000) to the media's central role in constituting social relationships and shared imagined worlds across time and space (Appadurai, 1996).

Research concerned with older people's lives in media and roles in society has to take into account both the variety of later lives and the multidimensionality of inequality that works on different levels of society and practice, extending from 'the economy and state, through the community and household to the individual' (Formosa and Higgs, 2013: 4). In his work, Roger Silverstone $(1994 ; 1999 ; 2006)$ focused on the media environment as structured by inequalities playing out in relationship between daily life and media use. The roll-out of e-government, e-care, and the general mediatization of social life highlight the increasingly dominant role of media, suggesting that sophisticated and sufficiently differentiated models and methods that explore how different people navigate the disorganized socio-technological environment must be deployed.

Attempts to address the intersection of general inequalities and media use typically draw on conventional class conceptualizations as context for studies of the relationship between socioeconomic factors, on one hand, and attitudes or orientations towards media, on the other hand. Interestingly, such work tends to find evidence for 'classed subjectivity' (Skeggs and Wood, 2011) among study participants, emphasizing how media can both enhance social and cultural participation in life as well as benefiting only the already privileged across the population (Hargittai, 2010). In such audience and reception studies, the social context is generally divided into 'working-class' and 'middle-class', and informants are selected or sampled based on conventional variables like income, occupation or education. ${ }^{2}$

If inequality in the much-vaunted networked information society transforms into an individualized, precarious enterprise, impacting in specific ways perceptions and practices of old age, it is paramount to explore what is actually going on in people's lives with media, particularly when it comes to those in later life. As argued by Roger Silverstone and Leslie Haddon (1996), we need to attend not just to the context of media use but to how the specificity of economic, political and social experience plays out in the experience of media and communication technologies (p. 46). Our first intervention is to point towards the necessity of grounded explorative daily life studies as a starting point for the development of more comprehensive understandings of the new media environment, 
fine-grained theorizing of the role of media in social and cultural hierarchies and developing a critical appreciation of how media shape stratification of the ageing experience. What we see as a promising way of studying the role of media in older people's lives with a cultural approach to social diversity and inequality (Savage, 2000) is to take inspiration from the field of cultural gerontology (Twigg and Martin, 2015) and to look to subjectivity and identity, the body and everyday life by means of ethnographic studies that are sensitized towards social diversity (Bottero, 2004). Coupled with inspiration from practice theory (Bourdieu, 1984; Reckwitz, 2002; Schatzki, 1999) attentive to both habitually embodied routine and discourse as systems of meaning that people draw on when they speak about their life worlds, social positions and place in society (Lindemann, 2007), this would move analyses towards grounded theorizing of the influence of media in social diversity. Exactly because of the dearth of specificity in research on the diverse and stratified lived and mediatized experience of later life, anthropological approaches are significant at this particular point in time, opening the way to larger, wide-ranging studies of (new) media and ageing.

\section{A life course approach to media and social diversity}

Inequality does not just happen to people when they get old as an effect of being old social diversity and disparities form during life and into old age and are embedded in everyday practices. Given the pervasive role of ICT in everyday life, we may expect issues of social diversity and inequality play out in media life. A second intervention we propose is a research design informed by a life course approach to ageing and mediatization - specifically when it comes to a heightened sensitivity towards the interaction of historical and individual time, and of intra-cohort diversity. The life course reflects how social and historical factors intersect with the personal biography and subjective experience (Elder, 1985; Hareven, 1996). It can be a tool for developing a chronicled consideration of people in later life as well as appreciating the interplay of media influences and historical changes over the course of a lifetime.

In a series of empirical case studies, Silverstone and Leslie Haddon (1996) explored the domestication of available mass and personal media through the life histories of the young elderly. Concerned with questions of access and inclusion, they remarked that the cohort shared experiences and reference points related to historical and technological conditions. On the other hand, differential experiences due to the diversity of biographies related to class and culture, social and geographical mobility, education, work trajectory, exposure to technology and so on made it difficult to generalize. Moreover, they found it 'wrong' to base assumptions on physical and mental decline and marginalization from society because of the late-life lifestyles represented in the study, as such issues were conditioned by biography. Patterns of use, acceptance and resistance to ICT were considered to be defined by a 'complex array' of social and cultural conditions (pp. 160-161). These benchmark studies on the domestication of media exemplify an exploring of power relationships in everyday (media) life achieved through the life course approach.

Empirical media research that addresses the intersection between general social diversity and media use is limited (Hargittai, 2008; Robinson, 2009). The relationship between inequality and mediatization tends to be framed in both optimistic terms - emphasizing the affordances of media in furthering democratization and inclusion of hitherto 
marginalized voices - and in pessimistic ones, emphasizing how new media acerbate existing inequalities and deepen digital divides. Notably, the concern with social inequality has been translated into research on digital divides between information rich and poor (Hepp and Hasebrink, 2013: 16). The concern for age-based digital divides in how people use media - and how to include older people in particular - have been consistent and underpin a considerable amount of the total research focusing on media in later life. The predominant method in such work tends to be the large-scale survey of media use, reducing older people to one or more arbitrary age groups. The maturing of the digital media environment has promoted a reframing of the concern from thinking in divides of 'eitheror' access and use to a focus on 'gradients of digital inclusion' - as, for example, the ability to make effective use of opportunities related to being online (Livingstone and Helsper, 2007). Another refinement is a diversification of variables for measurement of inclusion, more recently encompassing abilities to create and share content (Brants and Frissen, 2005; Haddon and Livingstone, 2009; Helsper et al., 2014). However, despite attempts to develop nuanced models for digital divides (Van Dijk and Hacker, 2003), it remains unclear what concepts like inclusion or literacy mean to people beyond preferred ICT practices; what the outcome of digital media use is or could be for the general public; or what the connection between general and digital inequality is (Hargittai, 2008; Helsper et al., 2014; Livingstone and Helsper, 2007). Leopoldina Fortunati (2008) notes how the debate on digital inclusion lacks 'robust sociological and political vision as well as anthropological awareness' (p. 1). Such general observations are particularly poignant when it comes to studies on digital inclusion and exclusion regarding ageing populations.

Several key trends and assumptions can be identified in the reviews of research on older people and media use specifically. In alignment with the assumption that being online is indisputably 'good' (Livingstone and Helsper, 2007: 673), Richardson et al. (2011) find that technology is constructed as either empowering or disempowering, or as a potential divider. The older person features in such studies as disabled, isolated and marginalized. Technology and media training (e.g. of balance, memory or social communication through forums or social networks) are suggested as solutions to the individual's experience of physical, mental and social decline. Attention to intersections between different social and cultural aspects or intergroup diversity is rare. The older person is in general just old, an ageing body; she is not considered to be a citizen, experienced, creative, playful or resourceful (Richardson et al., 2011: 142-146). While such work provides important knowledge and understanding of broad patterns related to the problems and possibilities of new media in relation to older people and the ageing society, only a marginal amount of research is found to approach older people as differentiated socially and culturally embedded subjects (Quinn, 2014; Richardson et al., 2011: 125; Sawchuk et al., 2014).

The research on older people and (new) media reflects how the divide-or-inclusion agenda has been based on top-down defined concepts originating in the concerns of policy makers and researchers, much less informed by the experiential reality of the people the research is supposedly concerned with. As such, it reflects a homogenization of age groups, where also more plural and diverse distinctions among young people have been overlooked (Livingstone and Helsper, 2007). With attention to the conceptual pitfalls of the research on the interrelationship between inequality and digital media, it has been suggested to turn to ethnographic studies of everydayness as a basis for the further 
development of what inclusion and benefits may mean to different people in different contexts (Helsper et al., 2014). This is a highly relevant suggestion if the concern is the inclusion of older people. The imposing of a categorical homogeneity of (old) age is at odds with the general insight of ageing studies: that old age in particular is heterogeneous due to the accumulation of the effects of different experiences and conditions during the individual's life (Dannefer, 1988; Hagberg, 2012: 191; Riley, 2013: 66). Matilda Riley (1988) early on highlighted the fallacy of 'cohort centrism' arguing that experiences of ageing and being old change with the changing of society. People take different paths in the historically changing society, and the ability to adapt to - or rather with - media technological transformations varies with the economic, cultural and social resources particular to gender, family structure, ethnicity and social class. Society is stratified by both inter- and intra-cohort disparities.

As consistently pointed out in studies on media concerned with older people, the life course perspective dismantles the all-to-easy notion of media 'generations' and other age-based patterns of use, divides, sensitizing analyses to the role of media in both inter- and intra-cohort social diversity (Hagberg, 2012; Quinn, 2014; see Richardson et al., 2011; Westlund and Weibull, 2011). A life course perspective integrates three aspects of time, providing a complex rendering of age and ageing:

- Individual time of biologically and culturally moulded life phases - such as childhood, adulthood and old age;

- Cohort time as the shared or stratified experience of people of the same chronological age;

- Historical time of political, economic and technological conditions and changes as the accumulation and transformation of social actions into social formations.

In addition, Gubrium and Holstein (2000) add a social constructivist approach to the life course as a 'social form' that people co-produce and use in their practices and more or less reflexive sense-making of the everyday (p. 1). The perspective is used for microand macro-level studies as well as for objective and subjective perspectives. Social gerontologist Chris Phillipson (2013) points towards the potential of the life course perspective to analyse and theorize larger social patterns within individual lives. With concern to social diversity and inequality as aspects of the transformation of ageing, Higgs and Gilleard (2006) argue that the life course perspective challenges assumptions of a relatively stable social structure by showing how 'occupational mobility (or the lack of it) no longer directly translates into variation in the material outcomes of either individuals or households' (p. 12). Yet, as an example of a general shift from a focus on social structures to individual agency, the perspective has mostly been used for biographical and life-historical studies, less so for media (Phillipson, 2013: 35-36).

People can be considered to be active co-creators whose sense-making practices, goals, expectations and activities vis-à-vis social relationships and institutional arrangements shape social structure (Clausen, 1991). As infrastructures for communication (Lievrouw and Livingstone, 2006), media form intrinsic part of the socio-historical time of older people's individual lives. People grow up and mature with particular media, move through life phases with media, and form affective relationships with and through their media. A biographical perspective of the life course sensitized towards differences 
in terms of intra-cohort life paths and experiences is an effective way of bypassing categorical homogeneity and cohort centrism. A simultaneous historicizing of lived experience in media life contributes to qualifying the understanding of who we are studying when looking into the role of media in later life. The life course perspective can be useful in focusing how media figure in establishing, maintaining and dismantling co-creative processes and interconnections. With its sensitizing of the interaction of historical and individual time as well as cohort diversity, the grid offers a crucial step of an operationalization of bottom-up exploring of how structures of social inequalities and ageing have been and are experienced and co-produced in 'everydayness' (Lefebvre, 1987).

\section{Ensemblematic approaches to media in daily life}

The third and final intervention we would like to make calls to focus empirical work on media repertoires: looking at the various ways people 'do' their media, rather than documenting distinct media usage in generic categories such as time spent, equipment used, and skills deployed. Our point is that people use media as ensembles and that media, beyond their capacities for communication, should be understood and studied in both their material as well as emotional contexts: in terms of what they are and what they mean. Research should be done with reference to how different media and practices during the life course combine to form distinct repertoires of use.

Beyond cohort centrism, the still dominant construction of old age as a more or less homogeneous category within media and communication studies draws on an out-dated mode of conceptualizing the relationship between people and media. The construction of a public for mass media, prevalent in 20th-century audience studies, meant a homogenization of the multitude of the mass society - often with a negative bias (about such mass media audiences as being passive and gullible). With the advent of new digital technologies, people have been framed as users, likewise homogenizing inasmuch as the term is without much social and historical context (Livingstone, 2005: 2). This in turn inspired a preoccupation with technology-driven age gaps and seeing media predominantly as assistant technologies people need to work with in order to 'fit' into society - rather than what Evan Illich called 'tools of conviviality' (2000[1973]): artefacts people can use as independent, self-governing bodies. As Vilém Flusser (1990) notes, such a construction reduces a person to a mere worker (homo faber) of information, rather than the more creative and empowered notion of 'an information processor, a player with information (homo ludens)' (p. 399). Instead, people tend to be framed as determined by a technology of interest (print, broadcast, computer, telecommunication), using single media (newspaper, magazine, radio, television, phone, Internet) with one-dimensional instrumental practices like operating the technology, searching and consuming information, and practising cognitive or motor skills.

The challenge to the idea of the mass audience, the proliferation of increasingly mobile and personalized media, the cultural and creative turns in media and cultural studies and a recognition of the increasingly networked yet fragmented nature of contemporary society (Castells, 2010; Hartley, 2012) promote the development of new understandings of people-media relationships. This is expressed in a shift towards theorizing media as practice (Couldry, 2012) with a renewed focus on what particular people do with or in relation to media - and what they say about media. Based on the concepts 
of home building and emotionally invested ownership, Elaine Lally (2002) went beyond the focus on the nuclear family and included also the young elderly in her explorative study on how households respond to the rapid spread of the computer, showing how media technologies function as a scaffolding of the self. The media as practice perspective opens up to understandings of media as integrated with power structures extending from economy and the state, through networks and communities to the everyday lived experience of the individual. Based on the scholarly argument that human life in general becomes mediatized (Couldry and Hepp, 2013; Hjarvard, 2008) and people's everyday awareness that media are ubiquitous and pervasive, emerging perspectives consider media less particular or special, rather seeing media as mundane and inseparably integrated into people's everydayness (Deuze, 2012; Hepp and Krotz, 2014; Madianou and Miller, 2013).

When empirically addressing the role media play in everyday later life, it is quite apparent that considering media as discrete technologies, types or genres (as has been the general approach in audience, reception and user studies) is problematic. With the proliferation of media - especially newer media for interpersonal communication - a core component of the current mediatization wave is the convergence and divergence of ubiquitous and pervasive media into an integrated environment. This point is critical, as a wide variety of media have been integrated differently into different experiences that in later life manifest in an 'entirety of media' (Hasebrink and Domeyer, 2012: 758). Regarding the specific question of social inequality as operationalized in digital divide and inclusion studies, people have multiple ways of integrating media into their everyday lives. As argued by Hepp and Hasebrink (2013), when the interest is the role of media in producing or maintaining inequality, it is problematic to focus on use and outcomes of single media because equalities and inequalities are multi-level and enforce or compensate each other (p. 16). Their work echoes earlier calls - for example, by Herman Bausinger as early as 1984, more recently by Couldry (2011) - to consider media as an ensemble, manifold or repertoire, rather than a series of distinct devices, platforms and uses. Linking an ensemblematic approach to media with the life course perspective means that different people at different locations (and social positions) in the world find different ways of being in the (new) media environment. Media constitute and represent, connect as well as isolate human beings. This is why it becomes crucial to engage directly with people's experience of reality as lived and experienced in what Lawrence Grossberg (1988) called 'the everyday world of media life' (p. 389).

To look at the full range of media repertoires of people situates analysis empirically on the level of individuals, focusing on their meaningful compositions of multiple media (Hasebrink and Domeyer, 2012: 760; Hasebrink and Popp, 2006). People's media ecologies or repertoires furthermore extend beyond discourse and include the material conditions of their mediatized environment. As formulated by Thorsten Quandt and Thilo von Pape (2010), the successive domestication and life of media in the home and household is integrated with the life course of its inhabitants. The home, like any other space wherein people work, play and live, becomes an integrated media environment - what Quandt and Van Pape call a 'mediatope' (deploying a biological metaphor). The range of activities and arrangements people have with media can be empirically approached as a repertoire. According to the repertoire approach, the compositions of media link closely to the ways someone expresses his or her individuality within the 
social and technological contexts he or she inhabits. As such, media repertoires are closely intertwined with social position, lifestyles and life projects (Hasebrink and Domeyer, 2012: 12-14; Hepp and Hasebrink, 2013: 13), which is why they can be useful in exploring differences, inequalities and stratification. It is this integration of media - in their double articulation (Silverstone, 1994) as ensembles of material objects and as symbolic content, integrated with embodied practice and sense-making over time that we consider as a most fruitful line of double articulated inquiry (Livingstone, 2007) when exploring the role of media in later life and old age. Combined with current perspectives from cultural gerontology research leads to new and specific research questions, including the following:

- How the domestication of new media into established practices and homes plays into the experience of ageing and of subjective age (Montepare, 2009; Ward, 2010);

- How old and new media contribute to the everyday level construction of third age lifestyles as informed by hierarchies of 'successful' ageing (Calasanti and King, 2011; Dannefer, 2003);

- What the role of media is in later-life transitions such as pensioning, decline of mobile and mental abilities, death of peers and in changes related to home and overall well-being (Oswald and Wahl, 2013; Peace, 2015).

\section{Conclusion}

As the accumulation of experiences throughout life makes old age socially and culturally highly diverse, it is urgent to be nuanced and to focus on difference and differentiation when studying older people. With the individualization of the life course, diversity and corresponding inequalities further increase. The parallel process of mediatization should inspire us to both historicize and make visible how people and media shape social and cultural differences.

In this review, we have argued that studies of new media and society can contribute to shedding light on inequalities in later life by deploying perspectives and methodologies that are sensitized towards social and cultural differences among older people. First, we argued that the categorical singularities created of people in later life and of media use are at odds with what we know about biological, social and cultural ageing, as it is out of sync with how people and their media should be seen as co-creating everydayness, including its social differences and inequalities. Next, we suggested to integrate insights from ageing studies with media theory and methodology in order to explore the different media lives that may - or may not - constitute inequalities in later life. As a way to empirically integrate cultural approaches to inequality, the life course perspective on ageing and media theory, we proposed the approach to media as an ensemble, recognizing how people integrate multiple media into 'mediatopes' where their lives play out in media.

It is striking how groups and segments of people generally still get partitioned according to traditional or under defined categories of age, class, and media uses. We have aimed to explore the various ways in which such approaches lack a certain depth of understanding by discussing emerging insights from media and communication studies, ageing studies and social stratification studies. Although such arguments can be made of any age cohort 
and different interest groups (such as refugees and disabled people), the study of older people is still in its infancy. Our ageing and mediatizing societies require rich, nuanced investigation specifically with reference to the ways those in later life experience inequality and manifest social diversity, especially since media and communication technologies have become so central in the political, economical and cultural coping strategies of ageing societies struggling with the challenges of a dependent old age.

\section{Author's Note}

The authors wish to establish equal contribution of authorship.

\section{Funding}

The author(s) disclosed receipt of the following financial support for the research, authorship, and/or publication of this article: Cecilie Givskov received financial support for the research from the VELUX Foundations, Tobaksvejen 10, 2860 Søborg, Denmark.

\section{Notes}

1. Ageing of the population refers to both the increase in the average (median) age of the population and the increase in the number and proportion of older people in the population.

2. We have to qualify that there seem to be no published studies at all that consider people in later life as makers of media - although their phone calls, texts and messages, online comments, social media profiles, game avatars (Zafar, 2011) as well as their idiosyncratic uses and arrangements of media are constitutive of their media lives. As John Hartley (2012) argues, people publishing their lives online can be considered to be a marker of a new cultural literacy (p. 111). This fits calls by media scholars for developing a distinct makers' perspective for the study of people and media in everyday life (Gauntlett, 2015; Jenkins, 2006).

\section{References}

Appadurai A (1996) Modernity at Large. Minneapolis, MN: University of Minnesota Press.

Bauman Z (2000) Liquid Modernity. Cambridge: Polity Press.

Bauman Z (2005) Liquid Life. Cambridge: Polity Press.

Beck U, Bonss W and Lau C (2003) The theory of reflexive modernization: problematic, hypotheses and research programme. Theory, Culture \& Society 20(2): 1-33.

Bottero W (2004) Class identities and the identity of class. Sociology 38(5): 979-997.

Bourdieu P (1984) Distinction: A Social Critique of the Judgement of Taste. Abingdon: Routledge Classics.

Brants K and Frissen V (2005) Inclusion and exclusion in the information society. In: Silverstone R (ed.) Media, Technology, and Everyday Life in Europe. Aldershot: Ashgate Publishing, pp. 21-32.

Calasanti T and King N (2011) A feminist lens on the third age: refining the framework. In: Carr DC and Komp K (eds) Gerontology in the Era of the Third Age: Implications and Next Steps. New York: Springer Publishing.

Castells M (2010) The Rise of the Network Society. Malden, MA: Blackwell Publishing.

Clausen JA (1991) Adolescent competence and the shaping of the life course. American Journal of Sociology 96: 805-842.

Couldry N (2011) The necessary future of the audience. and how to research it. In: Nightingale V (ed.) Handbook of Media Audiences. Chichester: Wiley-Blackwell, pp. 213-229.

Couldry N (2012) Media, Society, World: Social Theory and Digital Media Practice. Cambridge: Polity Press. 
Couldry N and Hepp A (2013) Conceptualizing mediatization: contexts, traditions, arguments. Communication Theory 23(3): 191-202.

Dannefer D (1988) What's in a name: an account of the neglect of variability in the study of ageing. In: Birren JE and Bengtson VL (eds) Emergent Theories of Aging. New York: Springer, pp. 354-384.

Dannefer D (2003) Whose life course is it anyway? Diversity and 'linked lives' in global perspective. In: Settersten RA (ed.) Invitation to the Lifecourse: Toward New Understandings of Later Life. Amityville, NY: Baywood Publishing Company, Inc, pp. 259-268.

Deuze M (2012) Media Life. Cambridge: Polity Press.

Elder GH (1985) Life Course Dynamics. Ithaca, NY: Cornell University Press.

Eurostat (2015) People in the EU - statistics on an ageing society: eurostat publication. Available at: http://goo.gl/0Fx8q3

Flusser V (1990) On memory (electronic or otherwise). Leonardo 23(4): 397-399.

Formosa M and Higgs P (2013) Introduction: the legacy of social class in gerontology. In: Formosa M and Higgs P (eds) Social Class in Later Life: Power, Identity, Lifestyle. Bristol: Policy Press, pp. 1-14.

Fortunati L (2008) Re-thinking e-inclusion. CIRN 2008, 5th Prato community informatics \& development informatics conference: ICTs for social inclusion: What is the reality? Prato, 27-30 October.

Gauntlett D (2011) Making is connecting. Cambridge: Polity Press.

Gilleard C and Higgs P (2011) The third age as a cultural field. In: Carr DC and Komp K (eds) Gerontology in the Era of the Third Age: Implications and Next Steps. New York: Springer Publishing, pp. 33-49.

Grossberg L (1988) Wandering audiences, nomadic critics. Cultural Studies 2(3): 377-391.

Gubrium J and Holstein BA (2000) Constructing the Life Course. New York: General Hall, Inc.

Haddon L and Livingstone S (2009) EU kids online: final report. Available at: http://eprints.lse. ac.uk/24372

Hagberg E (2012) Being the oldest old in a shifting technology landscape. In: Loos E, Haddon L and Mante Meijer E (eds) Generational Use of New Media. Bristol: Policy Press, pp. 89-107.

Hareven TK (ed.) (1996) Aging and Generational Relations: Life Course and Cross-Cultural Perspectives. New York: Aldine de Gruyter.

Hargittai E (2008) The digital reproduction of inequality. In: Grusky D (ed.) Social Stratification. Boulder, CO: Westview Press, pp. 936-944.

Hargittai E (2010) Digital na(t)ives: variation in internet skills and uses among members of the 'net generation'. Sociological Inquiry 80(1): 92-113.

Hartley J (2012) Digital Futures for Cultural and Media Studies. Cambridge: Polity Press.

Hasebrink U and Domeyer H (2012) Media repertoires as patterns of behaviour and as meaningful practices: a multimethod approach to media use in converging media environments. Participations: Journal of Audience \& Reception Studies 9(2): 757-783.

Hasebrink U and Popp J (2006) Media repertoires as a result of selective media use: a conceptual approach to the analysis of patterns of exposure. Communications: The European Journal of Communication Research 31(2): 369-387.

Helsper EJ, Van Deursen A and Eynon R (2014) Defining and measuring literacy nd resilience in a digital world; Panel of papers: new media and older people-age, narratives and normativities. In: Proceedings of the 5th ECREA conference, Lisbon, 11-15 November.

Hepp A and Hasebrink U (2013) Human interaction and communicative figurations: the transformation of mediatized cultures and societies. Communicative figurations working paper no. 2. Available at: http://www.kommunikative-figurationen.de/fileadmin/redak_kofi/ Arbeitspapiere/CoFi_EWP_No-2_Hepp_Hasebrink.pdf 
Hepp A and Krotz F (eds) (2014) Mediatized Worlds: Culture and Society in a Media Age. Basingstoke: Palgrave Macmillan.

Higgs P and Gilleard C (2006) Departing the margins: social class and later life in a second modernity. Journal of Sociology 42(3): 219-241.

Higgs P and Gilleard C (2015) Rethinking Old Age: Theorising the Fourth Age. London: Palgrave Macmillan.

Hjarvard S (2008) The mediatization of society: a theory of the media as agents of social and cultural change. Nordicom Review 29(2): 105-134.

Illich E (2001 [1973]) Tools of Conviviality. New York: Marion Boyars Publishers, Ltd.

Jenkins H (2006) Convergence culture. where old and new media collide. New York: New York University Press.

Lally E (2002) At Home with Computers. Oxford: Berg Publishers.

Lefebvre H (1987) The everyday and everydayness. Yale French Studies 73: 7-11.

Lievrouw L and Livingstone S (2006) Introduction to the updated student edition. In: Levrouw L and Livingstone S (eds) Handbook of New Media: Social Shaping and Social Consequences. London: SAGE, pp. 1-14.

Lindemann K (2007) The impact of objective characteristics on subjective social position. Trames 11(61/56): 54-68.

Livingstone S (2005) People living in the new media age: rethinking 'audiences' and 'users'. Paper presented on new approaches to research on the social implications of emerging technologies, Oxford Internet Institute, Oxford, 15-16 April.

Livingstone S (2007) On the material and the symbolic: Silverstone's double articulation of research traditions in new media studies. New Media \& Society 9(1): 16-24.

Livingstone $S$ and Helsper E (2007) Gradations in digital inclusion: children, young people and the digital divide. New Media \& Society 9(4): 671-696.

Lundby K (ed.) (2009) Mediatization. New York: Peter Lang.

Lunt P and Livingstone S (2011) Media Regulation: Governance and the Interests of Citizens and Consumers. London: SAGE.

Madianou M and Miller D (2013) Polymedia: towards a new theory of digital media in interpersonal communication. International Journal of Cultural Studies 16(2): 169-187.

Montepare J (2009) Subjective age: toward a guiding lifespan framework. International Journal of Behavioral Development 33(1): 42-46.

Oswald F and Wahl HW (2013) Creating and sustaining homelike places in residential environments. In: Rowles GD and Bernard M (eds) Environmental Gerontology: Making Meaningful Places in Old Age. New York: Springer, pp. 53-78.

Peace S (2015) Meanings of home and age. In: Twigg J and Martin W (eds) Routledge Handbook of Cultural Gerontology. London: Routledge, pp. 447-454.

Phillipson C (2013) Ageing and class in a globalized world. In: Formosa M and Higgs P (eds) Social Class in Later Life: Power, Identity, Lifestyle. Bristol: Policy Press, pp. 33-52.

Piketty T (2014) Capital in the Twenty-First Century. Cambridge, MA: Harvard University Press.

Quandt T and Von Pape T (2010) Living in the Mediatope: a multimethod study on the evolution of media technologies in the domestic environment. The Information Society: An International Journal 26(5): 330-345.

Quinn K (2014) Learning new tricks: the use of social media in later life. In: Harrington C, Bielby D and Bardo A (eds) Aging, Media and Culture. London: Lexington Books, pp. 183-192.

Reckwitz A (2002) Toward a theory of social practices. European Journal of Social Theory 5(2): 243-263.

Richardson M, Zorn T and Weaver C (2011) Older people and new communication technologies: narratives from the literature. In: Salmon CT (ed.) Communication Yearbook 35. New York: Routledge, pp. 121-152. 
Riley MW (1988) On the significance of age in sociology. In: Riley MW, Huber BJ and Hess BB (eds) Social Structures and Human Life. Newbury Park, CA: SAGE, pp. 1-14.

Riley T (2013) Self-initiated (re)education of digital technology in retired content creators. Northern Lights 11(11): 51-69.

Robinson L (2009) A taste for the necessary: a Bourdieuian approach to digital inequality. Information, Communication \& Society 12(4): 488-507.

Saul DJ (2014) 3 million teens leave Facebook in 3 years: the 2014 Facebook demographic report. iStrategyLabs report, 15 January. Available at: https://isl.co/2014/01/3-million-teens-leavefacebook-in-3-years-the-2014-facebook-demographic-report

Savage M (2000) Class Analysis and Social Transformation. Philadelphia, PA: Open University Press.

Sawchuk K, et al. (2014) Age, Narratives and Normativities, in Panel of Papers: New Media and Older People, The 5th ECREA Conference, November 11-15 2014, Lisbon, Portugal.

Schatzki T (1999) Social Practices: A Wittgenstinian Approach to Human Activity and the Social. Cambridge: Cambridge University Press.

Silverstone R (1994) Television and Everyday Life. London: Routledge.

Silverstone R (1999) Why Study the Media? London: SAGE.

Silverstone R (2006) Media and Morality: On the Rise of the Mediapolis. Cambridge: Polity Press.

Silverstone R and Haddon L (1996) Information and communication technologies and the young elderly. A report on the ESRC/PICT study on the household and information and communication technologies, SPRU CICT report series no. 13, March. Falmer: University of Sussex.

Skeggs B and Wood H (2011) Turning it on is a class act: immediated object relations with television. Media, Culture \& Society 33(6): 941-951.

Smith A (2014) Older Adults and Technology Use. PewResearchCenter Internet Project. Available at: http://www.pewinternet.org/2014/04/03/older-adults-and-technology-use

Twigg J and Martin W (2015) The challenge of cultural gerontology. Gerontologist 55(3): 353-359.

Van Dijk J and Hacker K (2003) The digital divide as a complex and dynamic phenomenon. The Information Society: An International Journal 19(4): 315-326.

Ward R (2010) How old am I? Perceived age in middle and later life. The International Journal of Aging and Human Development 71(3): 167-184.

Westlund O and Weibull L (2011) Generation, life course and news media use in Sweden 19862011. Northern Lights 11: 147-173.

Wilson C (2001) On the scale of global demographic convergence 1950-2000. Population and Development Review 27(1): 155-171.

Zafar A (2011) Physical video games may help the elderly psychologically. The Atlantic, 13 February. Available at: http://www.theatlantic.com/technology/archive/2011/02/physicalvideo-games-may-help-the-elderly-psychologically/71184

\section{Author biographies}

Cecilie Givskov is an assistant professor in the Department of Media, Cognition and Communication, University of Copenhagen. From 2013-2016, she has been part of a collective research project on ageing in media and older people's media use.

Mark Deuze is professor of Mediastudies in the Department of Mediastudies, University of Amsterdam, The Netherlands. Publications of his work include Media Work (Polity Press, 2007) and Media Life (Polity Press, 2012). 